\title{
Eubacterium fissicatena sp.nov. Isolated from the Alimentary Tract of the Goat
}

\author{
By MARGARET M. TAYLOR \\ The Hannah Research Institute, Ayr, Scotland \\ (Accepted for publication 21 February 1972)
}

\begin{abstract}
SUMMARY
A new species of Eubacterium has been isolated from the rumen and caecum of fistulated goats. This species, Eubacterium fissicatena, degraded the ribityl chain of riboflavin hydroxyethylflavin.
\end{abstract}

\section{INTRODUCTION}

The isolation of hydroxyethylflavin (HEF) as a bacterial degradation product of riboflavin was first reported by Miles \& Stadtman (I955), who used a partly purified culture of soil bacteria grown with excess riboflavin under anaerobic condition. HEF can be obtained from the urine of man after the ingestion of large doses of riboflavin (West \& Owen, 1969). HEF also occurs in the milk and urine of sheep and goats and the urine of ruminating kids and calves that are fed riboflavin, but not if the riboflavin is injected subcutaneously (Owen \& West, 1970). HEF can be isolated from the caecum of normal but not germ-free rabbits (Owen, West \& Coates, I970), which provides further evidence that HEF is a bacterial degradation product. In the present work, a bacteriological examination was made of samples from fistulated goats of rumen and caecal contents used for the chemical study of the bacterial enzyme system responsible for riboflavin degradation.

Eubacterium can be isolated from soil and from a wide variety of intestinal sources such as those of man, marine fish, sheep, foals "(Bergey's Manual of Determinative Bacteriology, 1957) and cows (Bryant \& Robinson, 1962). A new species of Eubacterium is described which has been isolated from the rumen and caecum of the goat and which degrades riboflavin to HEF.

\section{METHODS}

Samples were obtained from fistulated goats. The particulate matter and protozoa were removed from rumen samples by filtration and differential centrifugation and the bacterial deposit was inoculated into various media with excess riboflavin. Caecal samples were inoculated directly into the media. The most satisfactory fluid medium for the production of hydroxyethylflavin (HEF) contained $\mathrm{I} \cdot 5 \%$ Oxoid proteose-peptone, $0.25 \%$ Oxoid liver digest, $0.5 \%$ Oxoid yeast extract and $\mathrm{r} .0 \% \mathrm{NaCl}$ (YE broth) with about $0 . \mathrm{I} \%$ riboflavin RYE broth). The medium was sterilized at $\mathrm{I} 2 \mathrm{I}{ }^{\circ} \mathrm{C}$ for $\mathrm{I} 5 \mathrm{~min}$. A hot iron nail, as a reducing agent, was added to each tube just before inoculation. Oxoid blood agar base no. 2 with the addition of $0.5 \% \mathrm{NaCl}$ (YE agar) was used as a solid medium; riboflavin was added when required (RYE agar). The riboflavin-enriched mixed cultures were plated on RYE agar. Single colonies were inoculated into RYE broth. After 24 to $48 \mathrm{~h}$ of incubation, the broths were tested for HEF production. Tubes giving a positive reaction were plated for purity and further colonies tested for HEF production. This was continued until a pure culture had been obtained. HEF-producing colonies were identified by the orange colour of the 
oxidized HEF. During isolation, the solid media did not contain a reducing agent. When pure cultures had been obtained, $2 \mathrm{~g}$ reduced iron powder (British Drug Houses Ltd, Poole, Dorset), suspended in $10 \mathrm{ml}$ YE agar, was used in the lower layer of a doublelayer YE plate. The cultures were incubated under hydrogen in an anaerobic jar at $37^{\circ} \mathrm{C}$.

Eubacterium ruminantium (GAI95, B $_{1}$ C23), E. limosum (Butyribacterium rettgeri) (L34) were obtained from Dr M.P. Bryant, University of Illinois, U.S.A., Corynebacterium avidum (1352), E. aerofaciens (4I09), E. disciformans (364B), E. biforme (42I3B) from Dr M. Sebald, Pasteur Institute, Paris, E. ruminantium (ATCC17233) and B. rettgeri (ATCCI0825) from the American Type Culture Collection.

The cultures were stained by Gram's method and also to show cell wall structure (Mackie \& McCartney's Handbook of Bacteriology, 1962). Motility was examined in wet preparations from YE broth and in stab cultures in YE agar containing $0.25 \%$ agar. The fermentation of carbon sources using Durham tubes, production of indole, hydrolysis of cellulose and of Oxoid gelatin-charcoal discs and the reduction of nitrate were all tested in a $\mathrm{I} \%$ Oxoid peptone base and in a YE broth base.

For the examination of the fermentation products of glucose, the nutrient base $(200 \mathrm{ml})$ was filled into $8 \mathrm{oz}$ medical flat bottles fitted with perforated metal screw caps over rubber liners which allowed samples of gas to be withdrawn using a hypodermic syringe. Glucose was added to $0.5 \%(\mathrm{w} / \mathrm{v})$ either before sterilization of the base at $\mathrm{I} 15{ }^{\circ} \mathrm{C}$ for $10 \mathrm{~min}$, or as a Seitz-filtered solution after sterilization of the base. Either four iron nails or $0.15 \%$ cysteine were added aseptically as a reducing agent after sterilization. On one occasion about $4 \mathrm{~g}$ iron powder as a reducing agent was sterilized in the medium. The cultures were incubated for 7 days at $37^{\circ} \mathrm{C}$.

The gases in the headspace were analysed by gas-liquid chromatography using argon as the carrier gas (Czerkawski \& Clapperton, 1968). The samples for analysis of steam-volatile acids were prepared by the method of Cottyn \& Boucque (I968) and the determinations made by gas-liquid chromatography using Carbowax (20 M-TPS on Chromosorb G AWDMCS, $5 \mathrm{ft} \times \frac{1}{8}$ in) (W. G. Pye \& Co.). HEF was detected by thin-layer chromatography (Owen \& West, I968). The sulphuric acid-phenol method of Dubois, Gillies, Hamilton, Rebers \& Smith (1956) was used to measure the carbohydrate content of the basal media.

\section{RESULTS}

The cultures, when grown on RYE agar, initially formed translucent colonies that became bright green due to the production of HEF crystals and, after further incubation, turned crimson. On exposure to the air both green and crimson colonies turned bright orange which contrasted with the more yellow colour of the riboflavin in the medium. These colour changes were assumed to be due to the complex formation of HEF (Miles \& Stadtman, 1955). The highly reduced crimson and the oxidized orange colours were the distinguishing features of the isolates. Cultures $\mathrm{O}$ and $\mathrm{OA}$ were isolated from one rumen sample and 6, 6BO and 6 BOA from another. Cultures ThB and AzA were isolated from the caecum.

Rumen fluid in the media depressed HEF production by bacterial inocula from rumen and caecum. The mixture of acetate, iso-butyrate, iso-valerate and $n$-valerate reported by Bryant \& Robinson (1962) as being necessary for the growth of Eubacterium from the rumen of the cow also depressed HEF production by the pure isolates. However, bicarbonate increased HEF production and growth in the presence of the volatile fatty acid mixture of Bryant \& Robinson (1962).

Iron, either as a nail or powder, was the reducing agent that gave the best growth. Sodium 


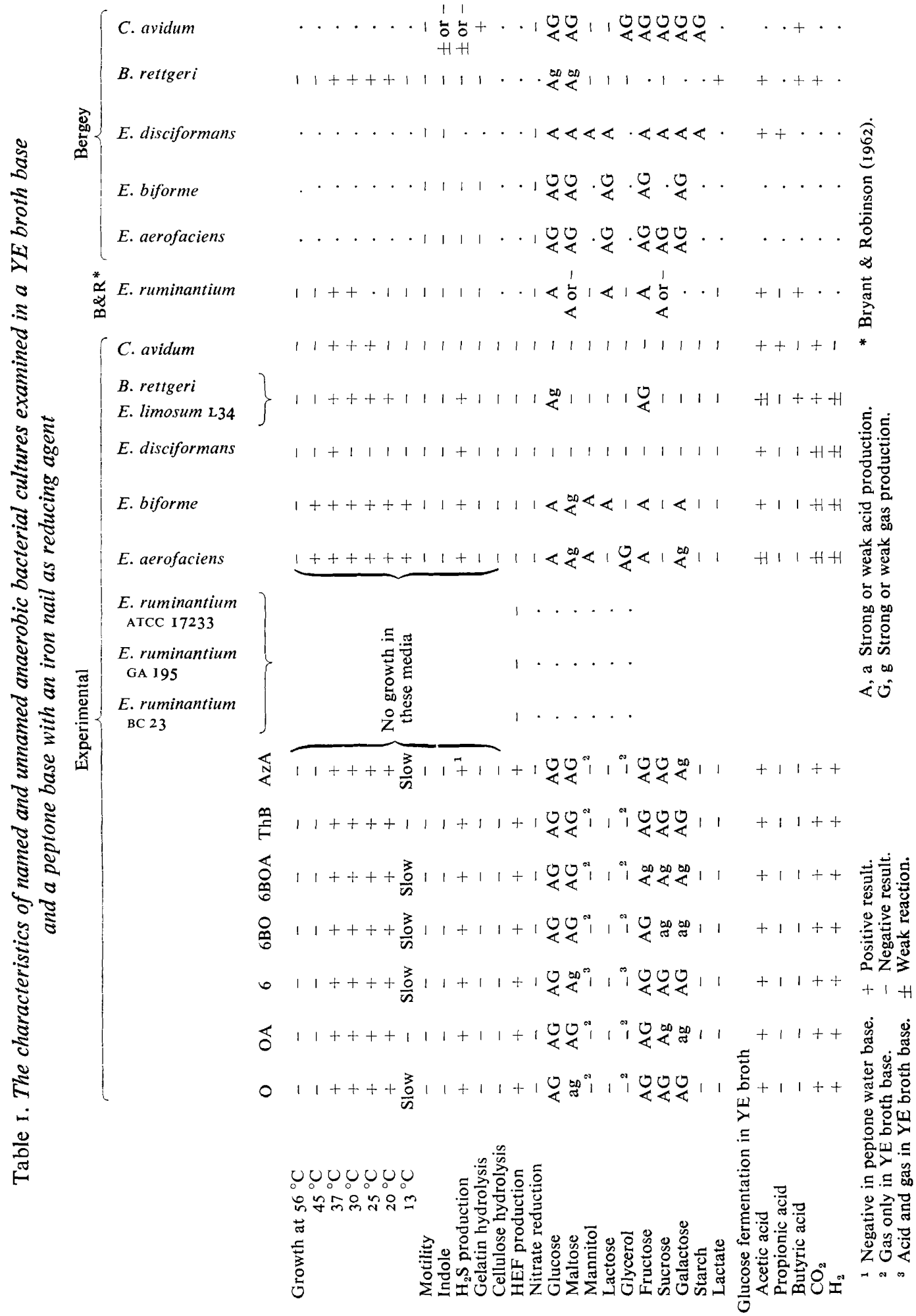


Table 2. The percentage of $\mathrm{CO}_{2}$ and $\mathrm{H}_{2}$ in the headspace of screw-cap bottles produced by cultures $O, 6, A z A$ from $Y E$ broth with and without glucose

\begin{tabular}{|c|c|c|c|c|c|c|c|c|}
\hline \multirow[b]{3}{*}{ YE broth } & & & \multicolumn{6}{|c|}{ Cultures } \\
\hline & \multicolumn{2}{|c|}{ Control } & \multicolumn{2}{|c|}{$\mathrm{O}$} & \multicolumn{2}{|c|}{6} & \multicolumn{2}{|c|}{$\mathrm{AzA}$} \\
\hline & $\mathrm{CO}_{2}$ & $\mathrm{H}_{2}$ & $\mathrm{CO}_{2}$ & $\mathrm{H}_{2}$ & $\mathrm{CO}_{2}$ & $\mathrm{H}_{2}$ & $\mathrm{CO}_{2}$ & $\mathrm{H}_{2}$ \\
\hline Without glucose & 0.12 & $0.0 \mathrm{I}$ & $\mathrm{I} \cdot 38$ & $I \cdot 36$ & I'OI & 0.84 & 0.93 & 0.85 \\
\hline$+0.5 \%$ glucose & 0.03 & 0.02 & $49 \cdot 9$ & $2 I \cdot 9$ & $55 \cdot I$ & $3 I \cdot 8$ & $36 \cdot 5$ & $15 \cdot 0$ \\
\hline
\end{tabular}

dithionite, sodium sulphite and cysteine were tried at various concentrations, but none gave such good growth as reduced iron. In the presence of sodium thioglycolate, growth was very erratic.

In liquid media, the unnamed cultures grew as small lanceolate bacilli 0.3 to $0.5 \mu \times 0.5$ to $\mathrm{I} \cdot \mathrm{\circ} \mu$. On solid media, they tended to form rod-shaped units 3 to $5 \mu$ long. A cell-wall stain showed these rod-shaped units to be multicellular. In some cases, chains of rods were formed and this was most noticeable with culture AzA. The bacilli were Gram-positive but were readily decolorized. There was no evidence of spore-formation or branching.

The isolates gave very similar results in all the identification tests and were distinct from the reference cultures (Table I). None of the isolates grew at 56 or $45^{\circ} \mathrm{C}$ and if growth occurred at $13{ }^{\circ} \mathrm{C}$ an incubation time of more than Io days was required. Optimal growth occurred at $37^{\circ} \mathrm{C}$. Motility was not observed in any of the cultures. All cultures produced $\mathrm{H}_{2} \mathrm{~S}$ from YE broth but strain AzA produced no $\mathrm{H}_{2} \mathrm{~S}$ from peptone water. The cultures were not strongly odiferous but 2- to 3-week-old cultures had a distinct faecal smell. Indole was not produced. Neither lactate nor nitrate was utilized; gelatin and cellulose were not hydrolysed. The isolates were actively fermentative, producing acid and gas from glucose, maltose, fructose, sucrose and galactose but not from mannitol, lactose, glycerol or starch when either YE broth and peptone water were used as basal media. A small amount of gas was produced from the peptone water and rather more from the YE broth base. The absence of acid was checked using an external indicator dye. When the cultures were grown in screw-cap bottles in YE broth without added glucose, a little gas was formed consisting of equal amounts of $\mathrm{CO}_{2}$ and $\mathrm{H}_{2}$ (Table 2) and unidentified carbohydrate material was present in the basal medium equivalent to $0.01 \%(\mathrm{w} / \mathrm{v})$ glucose in the peptone water and to $0.1 \%(\mathrm{w} / \mathrm{v})$ in the $\mathrm{YE}$ broth. Glucose $(0.5 \%)$ in the nutrient base gave a marked rise in $\mathrm{CO}_{2}$ and $\mathrm{H}_{2}$ production.

After 7 days at $37^{\circ} \mathrm{C}$, a small amount of methane was produced in YE broth by cultures 6 and $6 \mathrm{BOA}$ but not by any of the other isolates.

Both with named and unnamed cultures, glucose fermentation was less if glucose was added to the YE broth before sterilization rather than added aseptically as a Seitz-filtered solution (Table 3). Cysteine, as a reducing agent, also depressed glucose fermentation compared to an iron nail in the case of all the cultures examined, except Butyribacterium rettgeri. The named and unnamed Eubacterium cultures produced only acetic acid from the fermentation of glucose. Corynebacterium avidum produced acetic and propionic acids and $B$. rettgeri produced acetic and butyric acids. Reduced iron powder was not a suitable reducing agent for the examination of fermentation products since it reacted with the acid in the medium to give $\mathrm{H}_{2}$ gas.

None of the named cultures produced HEF, only the new isolates. Glucose in the medium suppressed HEF production with culture 6 but not with O, ThB or AzA. The production of HEF was a strictly anaerobic reaction and the ability to form this product was less under partial anaerobiosis. 
Eubacterium fissicatena sp.nov.

$46 I$

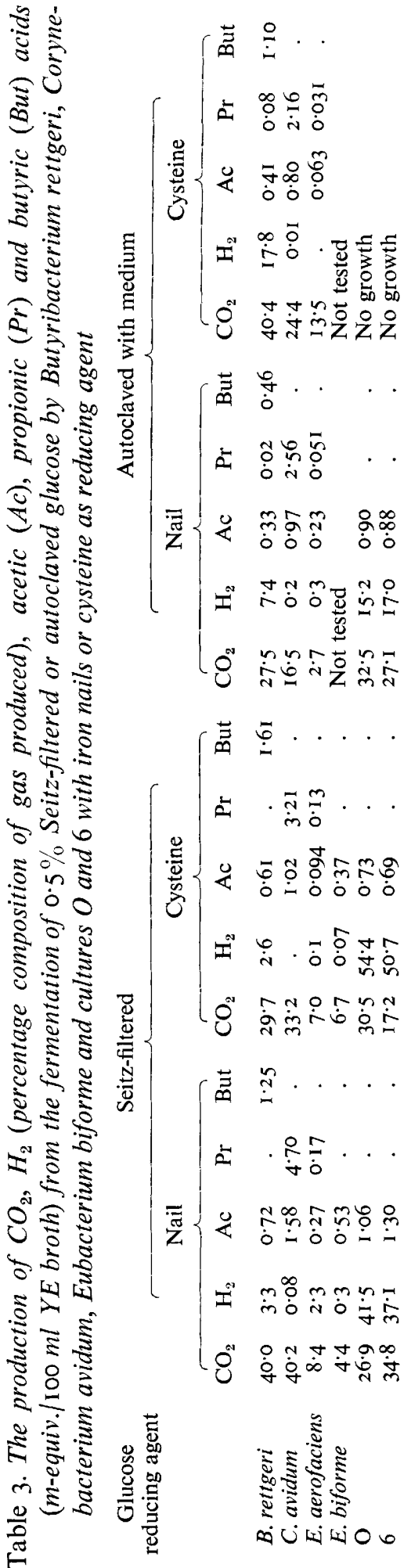




\section{DISCUSSION}

The isolates described in this work are the first pure cultures to produce HEF from riboflavin. Their morphology, their ability to produce gas from the basal medium, their active fermentation of carbohydrates and the products of glucose fermentation suggested that they were members of the genus Eubacterium. Since this genus is not well described in the literature a comparison was made with the species that were reported as showing biochemical reactions similar to those of the new isolates including Corynebacterium avidum and Butyribacterium rettgeri (Eubacterium limosum). The new cultures appeared to be intermediate between the gas-producing species (E. aerofaciens and E. biforme) and the non-gasproducing species ( $E$. ruminantium and $E$. disciformans). They did not ferment lactose, grew more readily than $E$. disciformans in the two basal media used in this work and, unlike E. ruminantium, did not require volatile fatty acids for growth.

The production of acid and gas from glucose by the organisms used in this work was influenced to a large extent by the conditions of growth. Eubacterium aerofaciens, E. biforme and Corynebacterium avidum are all reported in the literature as producing acid and gas from glucose. Although this could be confirmed by growth in a closed bottle (Table 3 ) when the cultures were grown in tubes plugged with cotton-wool and a Durham tube used to collect the gas, E. aerofaciens and E. biforme produced only acid and no gas, while $C$. avidum did not appear to attack glucose (Table I). The type of reducing agent and the method used to sterilize the glucose also influenced the products of fermentation (Table 3 ). The production of gas from the basal medium was presumably due to the fermentation of unidentified carbohydrates in the medium. The buffering capacity of the medium was apparently sufficient to give the appearance of gas formation without the associated acid production that could be detected by an indicator dye. These results show the importance of using a standard method for the growth of this group of anaerobes when fermentation products are to be determined.

The HEF-producing cultures are proposed as a new species: Eubacterium fissicatena - a small, easily decolorized Gram-positive lanceolate bacillus 0.3 to $0.5 \mu \times 0.5$ to $\mathrm{I} \cdot 0 \mu$ with a tendency to form chains of multicellular rods 3 to $5 \mu$ long; non-motile, non-sporeforming and non-branching; growth range is 13 to $37^{\circ} \mathrm{C}$ with optimum growth at $37^{\circ} \mathrm{C}$; degrade riboflavin to hydroxyethylflavin.

Old cultures have a faecal odour. They produce $\mathrm{H}_{2} \mathrm{~S}$ but not indole, they do not utilize nitrate or lactate nor hydrolyse gelatin or cellulose. They produce acid and gas from glucose, maltose, fructose, sucrose and galactose but not from mannitol, lactose, glycerol and starch. The fermentation products of glucose are $\mathrm{CO}_{2}, \mathrm{H}_{2}$ and acetic acid. Some strains form methane in the absence of glucose. The GC ratio of strain is $45.4 \%$.

Cultures O, 6 and AzA have been deposited with the National Collection of Industrial Bacteria as Eubacterium fissicatena (respectively NCIBI0444, I0445 and I0446).

The author thanks Miss J. McKaig, Miss B. Constable and Miss M. Ferguson for their valuable technical assistance, Miss G. Breckenridge and Mrs C. Faulds of the Nutrition Department for the chemical analysis, Dr E. C. Owen and the members of his staff for the confirmation of HEF production and Dr S. P. Lapage of the Central Public Health Laboratory, Colindale, for the $\mathrm{G} / \mathrm{C}$ ratios. 


\section{REFERENCES}

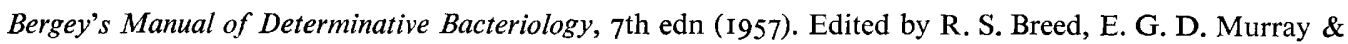
N. R. Smith. London: Baillière, Tindall \& Cox.

Bryant, M. P. \& Robinson, I. M. (1962). Some nutritional characteristics of predominant culturable ruminal bacteria. Journal of Bacteriology 84, 605-6I4.

CoTTYN, B. G. \& BoucQue, C. V. (1968). Rapid method for the gas-chromatographic determination of volatile fatty acids in rumen fluid. Agricultural and Food Chemistry 16, 105-107.

Czerkawski, J. W. \& Clapperton, J. L. (I968). Analysis of gases produced by metabolism of microorganisms. Laboratory Practice r7, 994-996, IOI 2.

Dubois, M., Gillies, K. A., Hamilton, J. K., Rebers, P. A. \& Smith, F. (1956). Colourimetric method for determination of sugars and related substances. Analytical Chemistry 28, 350-356.

Mackie \& McCartney's Handbook of Bacteriology. Ioth edn, p. I29 (1962). Edited by R. Cruikshank. Edinburgh \& London: E. \& S. Livingstone.

Miles, H. T. \& Stadtman, E. R. (I955). Isolation and characterization of 6, 7-dimethyl-9-2(2'-hydroxyethyl)-isoalloxazine as a bacterial fermentation product of riboflavine. Journal of the American Chemical Society 77, 5746-5747.

OWEN, E. C. \& WeST, D. W. (1968). Bacterial degradation of riboflavine. Journal of the Chemical Society pp. 34-46.

OWEN, E. C. \& WeSt, D. W. (1970). Metabolites of riboflavine in milk, urine and tissues of animals in relation to alimentary symbiotic bacteria. British Journal of Nutrition 24, 45-60.

OWen, E. C., WeSt, D. W. \& CoAtes, M. E. (1970). Metabolism of riboflavine in germ-free and conventional rabbits. British Journal of Nutrition 24, 259-267.

WEST, D. W. \& OWEN, E. C. (1969). The urinary excretion of metabolites of riboflavine by man. British Journal of Nutrition 23, 889-898. 